\title{
Perturbations of the optical properties of mineral dust particles by mixing with black carbon: a numerical simulation study
}

\author{
B. V. Scarnato ${ }^{1}$, S. China ${ }^{2}$, K. Nielsen ${ }^{1}$, and C. Mazzoleni ${ }^{2}$ \\ ${ }^{1}$ Naval Postgraduate School, 589 Dyer Road, Root Hall, Monterey, CA 93943-5114, USA \\ ${ }^{2}$ Michigan Technological University, Department of Physics and Atmospheric Sciences Program, 1400 Townsend Drive, \\ Houghton, MI 49931, USA
}

Correspondence to: B. V. Scarnato (bvscarna@nps.edu)

Received: 05 December 2014 - Published in Atmos. Chem. Phys. Discuss.: 27 January 2015

Revised: 10 May 2015 - Accepted: 24 May 2015 - Published: 25 June 2015

\begin{abstract}
Field observations show that individual aerosol particles are a complex mixture of a wide variety of species, reflecting different sources and physico-chemical transformations. The impacts of individual aerosol morphology and mixing characteristics on the Earth system are not yet fully understood. Here we present a sensitivity study on climaterelevant aerosols optical properties to various approximations. Based on aerosol samples collected in various geographical locations, we have observationally constrained size, morphology and mixing, and accordingly simulated, using the discrete dipole approximation model (DDSCAT), optical properties of three aerosols types: (1) bare black carbon (BC) aggregates, (2) bare mineral dust, and (3) an internal mixture of a $\mathrm{BC}$ aggregate laying on top of a mineral dust particle, also referred to as polluted dust.

DDSCAT predicts optical properties and their spectral dependence consistently with observations for all the studied cases. Predicted values of mass absorption, scattering and extinction coefficients (MAC, MSC, MEC) for bare BC show a weak dependence on the $\mathrm{BC}$ aggregate size, while the asymmetry parameter $(g)$ shows the opposite behavior. The simulated optical properties of bare mineral dust present a large variability depending on the modeled dust shape, confirming the limited range of applicability of spheroids over different types and size of mineral dust aerosols, in agreement with previous modeling studies. The polluted dust cases show a strong decrease in MAC values with the increase in dust particle size (for the same BC size) and an increase of the single scattering albedo (SSA). Furthermore, particles with a radius between 180 and $300 \mathrm{~nm}$ are characterized by a decrease in
\end{abstract}

SSA values compared to bare dust, in agreement with field observations.

This paper demonstrates that observationally constrained DDSCAT simulations allow one to better understand the variability of the measured aerosol optical properties in ambient air and to define benchmark biases due to different approximations in aerosol parametrization.

\section{Introduction}

Black carbon (BC), a distinct type of carbonaceous aerosol particle, is produced by incomplete combustion of fossil and biomass fuels. $\mathrm{BC}$ is a strong light absorber and therefore can contribute to atmospheric warming and surface dimming. Estimates of direct BC radiative forcing (DRF) are highly uncertain and range from 0.2 to $1.2 \mathrm{~W} \mathrm{~m}^{-2}$ at the top of the atmosphere (TOA) (Bond et al., 2013). Two main sources of DRF uncertainty are (1) estimates of BC spatial distribution and (2) interaction of $\mathrm{BC}$ with electromagnetic waves (EMWs) upon emission and after aging in the atmosphere. Realistic modeling of BC spatial distribution relies on proper parametrization of emission, lifetime and vertical distribution (Samset et al., 2013; Bond et al., 2013), while appropriate modeling of $\mathrm{BC}$ interaction with EMWs relies on proper parametrization of aerosol shape, chemical composition and state of mixing with other aerosol compounds. Comparison between predicted spatial concentrations of $\mathrm{BC}$ from chemical transport models and AERONET (Aerosol Robotic Network) measurements shows consistent biases. Specifically, the fraction of aerosol column (extinction) attributable to ab- 
sorption, the aerosol absorption optical depth (AAOD), is generally underestimated by models compared to values retrieved by AERONET (Bond et al., 2013; Koch et al., 2009; Kim et al., 2008; Klingmüller et al., 2014). The sources of discrepancy are not well understood. In order to estimate BC DRF "consistently" with observations, scaling factors on the order of 2-3 need to be introduced to BC emission estimates to match observed AAOD values.

In Koch et al. (2009) BC predictions from the AeroCom model inter-comparison project showed a low model bias for AAOD, but an overestimation of surface and upper BC concentrations at lower latitudes. The authors suggest that most models are underestimating BC absorption and recommend to work on improving estimates of refractive indices, particle size, and optical effects of BC mixing. Many transport models assume $\mathrm{BC}$ to be externally mixed with other aerosol compounds, while few models assume that $\mathrm{BC}$ is homogeneously internally mixed with other aerosol compounds (Bond and Bergstrom, 2006; Koch et al., 2009). Differences in the representation of the aerosol mixing (i.e., BC with non-absorbing aerosols) lead to different absorption values, which compared to measurements are too small in the case of external mixing and too high for the case of homogeneous internal mixing. Less often an encapsulation of a spherical and homogeneous absorbing core surrounded by a spherical and homogeneous non-absorbing host material is adopted (coreshell configuration), which gives more realistic magnitudes of absorption (Jacobson, 2014, 2001).

Despite that, the core-shell configuration cannot always represent the absorption variability in the laboratory and field observations (Adachi et al., 2010; Bueno et al., 2011; Bond et al., 2013; Cappa et al., 2012b, a). The latter might be due to the miss-representation of the $\mathrm{BC}$ particle aggregation and mixing, as shown by more detailed light scattering modeling studies performed by Kahnert (2010b), Scarnato et al. (2013) and Adachi and Buseck (2013). Recent studies show that internal mixing of $\mathrm{BC}$ with other aerosol materials in the atmosphere can alter its aggregate shape (Zhang et al., 2008; Xue et al., 2009; Cross et al., 2010; China et al., 2013), absorption of solar radiation (Bueno et al., 2011; Cappa et al., 2012b), and radiative forcing (Adachi et al., 2010; Kahnert et al., 2012). China et al. (2014), furthermore, characterized the predominant mixing and morphology types observed with the electron microscopes from samples collected in different locations and for different sources (i.e., biomass burning aerosol and vehicle exhaust) by classifying $\mathrm{BC}$ into four main classes (bare BC, inclusions, thinly coated and embedded $\mathrm{BC}$ ); similar classes where identified by Scarnato et al. (2013) for laboratory-generated mixtures of BC and sodium chloride (an aerosol mixture resembling dirty marine aerosol).

Several field campaigns have been showing the occurrence of internal mixing of $\mathrm{BC}$ with dust aerosols in the accumulation mode (e.g., Clarke et al., 2004; Liu et al., 2008). During transport and aging in the atmosphere, various processes can result in the formation of multi-component aerosols containing dust, including (i) heterogeneous chemistry, (ii) adsorption of water vapor on dust particle surfaces, (iii) cloud processing, and (iv) coagulation of dust with other aerosol or cloud particles (see Usher et al., 2003). On a global scale, bare dust is estimated to cool Earth's atmosphere. Mineral dust TOA DRF constitutes, as BC aerosols, one of the major uncertainties in climate studies $\left(-0.6\right.$ to $0.4 \mathrm{~W} \mathrm{~m}^{-2}$ ) due to the lack of knowledge of both dust spatial distribution and interaction with EMWs. Parametrization of mineral dust optical properties is also a complex problem, as its optical properties are a strong function of (i) the relative abundance of various minerals, (ii) how the minerals are mixed together in an aerosol particle, and (iii) the particle shape. Those factors depend on dust origins and, therefore, on the elemental composition of surface soils but also on the dust lifting production mechanism and dust chemical and physical transformations (i.e., compositional separation) during aging and transport in the atmosphere. Many field studies reported changes in composition during dust transport (i.e., Prospero et al., 1981; Chester et al., 1972; Hansell Jr. et al., 2011; Nousiainen, 2009). Observations from the ground and from aircraft over the Sahara show considerable variation and uncertainty in the optical properties of mineral dust (McConnell et al., 2010; Sokolik and Toon, 1999). The large variability is attributed to the mineral dust particles' variability in size distributions, chemical composition and morphology. Furthermore, different modeling studies on light interaction with mineral dust aerosol show (i) the limited range of applicability, over different types of mineral dust aerosols, of commonly used shapes such as spheres (adopted in Mie computations) and spheroids (adopted in T-matrix computations and in AERONET retrieval) (Merikallio et al., 2011), (ii) the inability of Mie simulations to accurately reproduce the magnitude and wavelength peak positions of the mass absorption/extinction coefficients common for angularly shaped particles (as shown by Hansell Jr. et al. (2011) in the infrared region), and (iii) the effect of non-spherical dust particles on the total RF (radiative forcing) is 55/5\% (ocean/land) at the TOA and $15 \%$ at the bottom of the atmosphere (BOA) for both land and ocean, while local radiative heating within a dust plume causes enhancements of $20 \%$ of RF (Otto et al., 2011).

Internal mixing of mineral dust and $\mathrm{BC}$ aggregates has a strong impact on the optical properties of originally externally mixed aerosol, on their radiative forcing (Mishra et al., 2012; Sokolik et al., 2001) and on spatial and temporal distribution of precipitations, for example during the monsoon in Asia (Lau and Kim, 2006) or the African jet streams (Reale et al., 2011).

An accurate parametrization of aerosol optical properties due to variability in morphology and mixing with other aerosol compounds is crucial for a number of disciplines involving not only radiative forcing analysis (Bond et al., 2013) and global and regional aerosol modeling (Samset et al., 
2013; Kahnert, 2010b) but also aerosol-cloud interactions, visibility and precipitation forecasts (Lau and Kim, 2006) and, furthermore, remote sensing of atmosphere and ocean color (Russell and Heintzenburg, 2000; Durkee et al., 2000; Yoshida et al., 2013).

For example, retrievals of aerosol (and ocean) properties require the assumption of (1) the scattering phase function, (2) single scattering albedo (SSA), (3) estimates of ozone absorption and molecular scattering, and (4) for satellite applications, estimates of surface reflectance/albedo. Both orbital and ground-based remote sensing techniques use a preselected library of aerosol types in the analysis of radiometric data. The computations of optical properties for the library often make use of spherical shape assumptions. The assumptions of the mineral dust particles' shape may vary in the retrieval algorithms. AERONET retrieval assumes mineral dust particles to be spheroidal (Dubovik et al., 2006), while MISR (Multi-angle Imaging SpectroRadiometer) retrievals (version 16+) use spheroidal, grains, plates and spherical shapes (Kalashnikova et al., 2013). The retrieval algorithms select an aerosol type based on the best fit to radiance measurements (i.e., Deuze et al., 2001; Hasekamp et al., 2011).

The capability of the satellite and AERONET aerosol global network to provide spatiotemporal distributions of both dust and $\mathrm{BC}$ at different spatial scales relies on how well the aerosol library used in the retrieval "fits" the aerosol mixture in the atmosphere; therefore, it is dependent on the accuracy of the retrieval assumptions on dust and $\mathrm{BC}$ optical properties. Therefore, non-sphericity and chemical anisotropy of the particles are sources of potential inaccuracy and biases of data products. These inaccuracies may affect the retrieval of aerosol characteristics, such as refractive index, size, aerosol optical depth, aerosol absorption optical depth, etc. (e.g., Scarnato et al., 2013, and references therein).

In this paper we present an "observationally constrained" sensitivity study of the optical properties of BC aggregates internally mixed with mineral dust aerosols in the UVIR spectral range (computationally intensive). The spectral range used in this study is of interest for applications in climate modeling, remote sensing of aerosol and ocean properties, and visibility forecast. Computations are performed using the discrete dipole approximation (DDA - DDSCAT7.3) (Draine and Flatau, 1994), a technique for modeling particles with complex shape, chains and aggregates with anisotropic mixing. DDSCAT is based on the direct solution of the Maxwell equations without reference to the wave equation, which is usually used in the treatment of light scattering by simple shapes, such as sphere and spheroids. Synthetic particle design for the DDSCAT calculations is based upon single-particle electron microscopy of bare $\mathrm{BC}$, bare dust and $\mathrm{BC}$ dust (internally mixed particles of $\mathrm{BC}$ on the surface of a dust particle collected in the atmosphere from different locations of the globe).

\section{Method}

\subsection{Description of the synthetic particles}

\subsubsection{Black carbon aggregates}

We generate synthetic BC aggregates by aggregation of monomers in random walk (Richard and Davis, 2008; Richard et al., 2011). The synthetic BC aggregates are characterized by a volume equivalent radius $\left(a_{\text {eff }}\right.$ also defined as the radius of a sphere containing all the volume of the particle) between 82 and $144 \mathrm{~nm}$, a constant monomer diameter of $40 \mathrm{~nm}$ and an open-chain-like structure. Such values have been observationally constrained after processing electron microscope images of several aerosol samples collected in field campaigns carried out in different geographical locations - such as California's Sacramento Valley (CARES); Pico Island, Azores (PICO); Mexico City, Mexico (MILAGRO); and Detling, England (ClearfLo) - where internal mixture of $\mathrm{BC}$ and mineral dust have been observed.

The reader should be aware that the morphological characterization of the ambient aerosol is determined by processing 2-D electron microscope images on aerosol particles laying on a substrate and assuming orientational anisotropy over a statistically representative sample. Therefore, as a minor secondary aspect of the paper, we investigated the appropriateness of the standard method adopted in literature to estimate a morphological descriptor, such as the monomer number of $\mathrm{BC}$ aggregates by performing image processing of 2-D projections of synthetic BC fractal aggregates. Image processing of synthetic BC fractal aggregates allowed, as well, assuring that the synthetic particles have similar 2-D properties to those collected in the atmosphere.

In this paper, we describe the $\mathrm{BC}$ aggregate morphology and chain-like structure in terms of (1) fractal dimension, porosity (Shen et al., 2008; Scarnato et al., 2013) and convexity (as descriptors of the chain topology), (2) aspect ratio, and (3) roundness.

$\mathrm{BC}$ particles can be represented as fractals, where each particle is described as an aggregate with monomers of the same size, approximately obeying the following scaling law

$N_{i}=k_{0}\left(R_{\mathrm{g}} / r_{\mathrm{m}}\right)^{D_{\mathrm{f}}}$,

where $N$ is the number of monomers per aggregate with $i=$ (estimated, true), $R_{\mathrm{g}}$ is the radius of gyration, $r_{\mathrm{m}}$ is the monomer radius, $k_{0}$ is the fractal prefactor, here used a value of $k_{0}=1.6$ (Liu et al., 2008), and $D_{\mathrm{f}}$ is the mass fractal dimension.

$R_{\mathrm{g}}$ is the root-mean-square distance from the center of each monomer to the aggregate center of mass. As often it is difficult to measure $N_{\text {true }}$ from 2-D projections, for particles with $D_{\mathrm{f}}<2, N_{\text {true }}$ is typically estimated as the ratio of the projected area of the aggregate $\left(A_{\mathrm{a}}\right)$ and the mean projected 
Table 1. Characteristics of the modeled aerosol particles. Dust particles have an aspect ratio for all three axes (AR) of 1.75 in all cases (oblate). The optical properties of dust, BC and mixtures were averaged over 1000 random orientations.

\begin{tabular}{lllr}
\hline Aerosol Type & Legend & Target shape in study & $a_{\text {eff }}[\mathrm{nm}]$ \\
\hline \multirow{2}{*}{ Dust } & S1, E1 & Rectangular prism, Ellipsoid & 180 \\
& S2, E2 & Rectangular prism, Ellipsoid & 280 \\
& S3, E3 & Rectangular prism, Ellipsoid & 500 \\
& S4, E4 & Rectangular prism, Ellipsoid & 700 \\
& S5, E5 & Rectangular prism, Ellipsoid & 1000 \\
\hline Black carbon & BL1 & BC aggregate with 70 monomers & 80 \\
& BL2 & BC aggregate with 100 monomers & 100 \\
& BL3 & BC aggregate with 200 monomers & 120 \\
& BL4 & BC aggregate with 300 monomers & 140 \\
\hline Mineral dust and BC & BL2S1 & Rectangular prism mixed w BC (BL2+S1) & 190 \\
& BL2S2 & Rectangular prism mixed w BC (BL2+S2) & 290 \\
& BL2S3 & Rectangular prism mixed w BC (BL2+ S3) & 503 \\
& BL2S5 & Rectangular prism mixed w BC (BL2 + S5) & 1010 \\
\hline
\end{tabular}

area of a monomer $\left(A_{\mathrm{p}}\right)$ in the aggregate (Oh and Sorensen, 1997; Samson et al., 1987).

$N_{i}=K_{\mathrm{a}}\left(A_{\mathrm{a}} / A_{\mathrm{p}}\right)^{\alpha}$,

where $\alpha$ is an empirical projected area exponent and has a typical value of 1.09 , while $k_{\mathrm{a}}$ has a value of 1.15 . The sensitivity of $N_{i}$ to the values of $\alpha$ and $k_{\mathrm{a}}$ has been discussed previously (China et al., 2014).

The aspect ratio (AR) of the fractal aggregate, is defined as the ratio of the major axis $(A)$ to the minor axis $(B)$. Larger values of the aspect ratio indicate a more elongated particle.

$\mathrm{AR}=\frac{A}{B}$

The roundness of a fractal aggregate, is defined as the ratio of the projected area $\left(A_{\mathrm{a}}\right)$ of the particle to the area of a circle with a diameter equal to the maximum length $\left(L_{\max }\right)$ of the particle.

Roundness $=\frac{4 A_{\mathrm{a}}}{\pi L_{\max }^{2}}$

The chain-like structure has been characterized in terms of convexity, porosity and fractal dimension (see Eq. 1). The convexity ( $C$; also known as solidity) is defined as the ratio of the $A_{\mathrm{a}}$ of the particle to the area of the smallest convex polygon in which the particle is inscribed (convex hull polygon-CHP). The polygon is calculated based on the boundary enclosing the foreground pixels of a binary image using straight-line segments to each outermost point.

$C=\frac{A_{\mathrm{a}}}{\mathrm{CHP}}$
The porosity $(P)$ of the fractal aggregates is defined by Shen et al. (2008) as

$P=1-\left[\left(\beta_{2}+\beta_{3}-\beta_{1}\right)\left(\beta_{3}+\beta_{1}-\beta_{2}\right)\left(\beta_{1}+\beta_{2}-\beta_{3}\right)\right]^{1 / 2}$,

where $\beta_{i}=I_{i} /\left(0.4 \rho_{1} V_{1} a_{\mathrm{eff}}^{2}\right)$ is a dimensionless quantity, $I_{i}$ with $i=(1,2,3)$ is the moment of inertia tensor, $\rho_{1}$ is the density and $V_{1}$ the volume of BC aggregates (see Shen et al., 2008).

Morphological descriptors of synthetic $\mathrm{BC}$ aggregates are calculated from projected images of 50 random particle orientations.

\subsubsection{Mineral dust aerosol}

The morphology of suspended mineral dust might take various forms, as natural dust is an aggregate of internally mixed minerals. Different field studies show AR median values ranging between 1.4 and 1.9 (Chou et al., 2006; Clarke et al., 2004; Reid et al., 2003; Kandler et al., 2006; Dubovik et al., 2006; Mishra et al., 2012). In this study, we modeled dust aerosols as spheroids and rectangular prisms with an intermediate aspect ratio (compared to the refereed literature) of 1.75 , which has also been found in CARES, PICO, MILAGRO and the ClearfLo field campaigns (see Table 3).

We summarize the characteristics of the synthetic/modeled aerosol particles in Table 1. Dust particles with a smaller radius are representative of particle size distribution of longlived distant-transported accumulation-mode airborne dust. The largest radius is representative of the particle's size near the dust emission sources.

\subsection{Computation of optical properties}

We have numerically simulated the optical properties for an ensemble of bare mineral dust, bare open-chain-like BC aggregates and internal mixtures of $\mathrm{BC}$ and mineral dust (see 
Table 2. References of the wavelength-dependent refractive indices and density values used for BC and mineral dust. The Chang and Charalampopoulos (1990) values at about $550 \mathrm{~nm}$ are $1.77-0.63 i$, which are lower than the value of $1.95-0.79 i$ suggested by Bond and Bergstrom (2006).

\begin{tabular}{lll}
\hline Aerosol compounds & Reference refractive indices & Density $\left[\mathrm{g} \mathrm{cm}^{-3}\right]$ \\
\hline Black carbon & Chang and Charalampopoulos (1990) & 1.8 \\
Mineral dust & Wagner et al. (2012) & 2.6 \\
\hline
\end{tabular}

Table 1). Optical properties of the binary mixtures are modeled using a DDA model (DDSCAT.7.3) (see for model details Draine and Flatau, 1994, 2010). Numerical simulations have been carried out at the specific spectral channels of the AERONET Cimel radiometer (340, 380, 440, 500, 675, 870, $1020 \mathrm{~nm}$ ) plus at the $550 \mathrm{~nm}$ wavelength for comparison with literature values. Optical properties have been averaged over 1000 random orientations, reference refractive indices are listed in Table 2.

The following are the optical properties discussed in this study.

1. The mass absorption, scattering and extinction coefficients (MAC, MSC and MEC):

$$
\begin{aligned}
& \mathrm{MAC}=C_{\mathrm{abs}} / \text { mass }, \\
& \mathrm{MSC}=C_{\text {scat }} / \text { mass }, \\
& \mathrm{MEC}=C_{\mathrm{ext}} / \text { mass, } \\
& \text { mass }=\rho \frac{4}{3} \pi a_{\mathrm{eff}}^{3}=\frac{4}{3} \pi\left(\rho_{1} a_{1, \mathrm{eff}}^{3}+\rho_{2} a_{2, \mathrm{eff}}^{3}\right),
\end{aligned}
$$

where $C_{\text {abs }}, C_{\text {scat }}$ and $C_{\text {ext }}$ indicate the absorption, scattering and extinction cross sections, $\rho_{1,2}$ is the density (index 1 indicates $\mathrm{BC}$ and index 2 mineral dust). MAC and MSC are necessary to calculate the effects of mass concentrations simulated by chemical transport models on radiative transfer. MAC and SSA (defined in Eq. 14) are relevant to determinate the balance between negative and positive forcing.

2. The aerosol absorption, extinction, and scattering Ångström exponent (AAE, EAE, SAE) computed from the slope of the linear fit passing though MAC, MSC and MEC curves (in log-log scale). The AAE and EAE are typically used as indicators of aerosol type and size.

$$
\begin{aligned}
& \mathrm{AAE}=\frac{-\Delta \log (\mathrm{MAC})}{\Delta \log (\lambda)} \\
& \mathrm{EAE}=\frac{-\Delta \log (\mathrm{MEC})}{\Delta \log (\lambda)} \\
& \mathrm{SAE}=\frac{-\Delta \log (\mathrm{MSC})}{\Delta \log (\lambda)}
\end{aligned}
$$

3. The SSA is calculated as

$$
\mathrm{SSA}=C_{\text {scat }}(\lambda) / C_{\text {ext }}(\lambda)
$$

Table 3. Synthesis of morphological descriptors for BC and mineral dust aerosol particles sampled in various field campaigns.

\begin{tabular}{llll}
\hline Aerosol type & $\begin{array}{l}\text { Projected area } \\
\text { equivalent radius } \\
{[\mathrm{nm}]}\end{array}$ & $\mathrm{AR}$ & $\begin{array}{l}r_{\mathrm{m}} \\
{[\mathrm{nm}]}\end{array}$ \\
\hline Dust & $250-810$ & $1.08-1.75$ & \\
Black carbon & $90-140$ & $1.39-1.98$ & $34-49$ \\
\hline
\end{tabular}

where $C_{\text {abs }}, C_{\text {scat }}$ and $C_{\text {ext }}(\lambda)$ are defined in Eqs. (7), (8) and (9).

4. The asymmetry parameter is defined as

$$
g=1 / 2 \int_{0}^{\pi} \cos (\theta) \sin (\theta) P(\theta) \mathrm{d} \theta
$$

where $P(\theta)$ is the scattering-phase function and $\theta$ is the scattering angle.

SSA and $g$ are the two fundamental parameters necessary to perform calculations of aerosol radiative properties (e.g., Chylek and Wong, 1995).

\section{Results}

\subsection{BC internally mixed with dust}

We have observed BC internally mixing with suspended mineral dust (BC particles laying on top of dust particles) in various field campaigns. In Fig. 1, we show a composite of SEM (scanning electron microscope) images from aerosol samples collected: (a) in an urban location $10 \mathrm{~km}$ north of downtown Mexico City (MILAGRO, March 2006); (b) $40 \mathrm{~km}$ downwind of the Sacramento urban area in the forested Sierra Nevada foothills, California, USA (Zaveri et al., 2012); (c) in a rural site in Detling, UK (ClearfLo, January-February, 2012); and (d) at Pico Mountain Observatory, Azores Islands (Portugal) in the North Atlantic Ocean (Honrath et al., 2004; Dzepina et al., 2015).

The morphological characteristics of the $\mathrm{BC}$ and mineral dust particles are summarized in Table 3. The values reported for BC are in agreement with Adachi et al. (2007). 


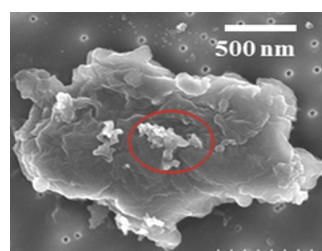

(a) Milagro

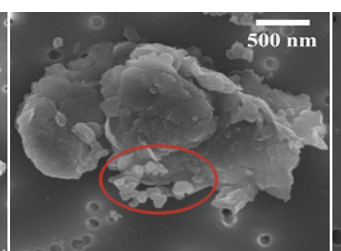

(b) CARES

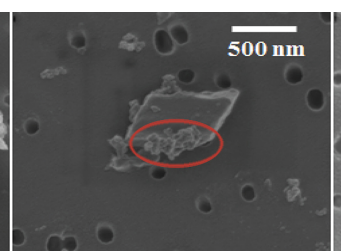

(c) ClearfLo

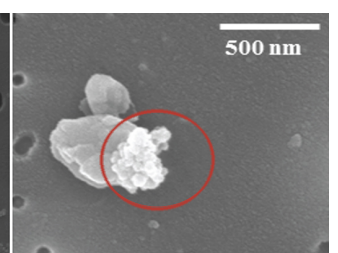

(d) Pico

Figure 1. SEM images of internally mixed mineral dust and BC particles observed during various field campaigns: (a) Mexico City, Mexico (Megacity Initiative: Local and Global Research Observations (MILAGRO) 2006); (b) a silicon rich dust particle internally mixed with BC, Sacramento, California, USA (2012); (c) a complex internal mixture of multiple aerosol components, Detling, UK (Clear Air for London (ClearfLo), 2012); and (d) a dust particle with plate-like structure (clay mineral) from Pico Mountain Observatory, Pico island, Azores (Portugal) in the North Atlantic Ocean (2012). Red circles identify BC on the surface of mineral dust particles.

(a)

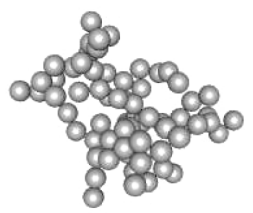

$\mathrm{BL} 1$

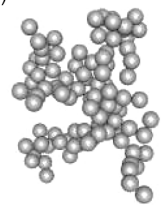

$\mathrm{BL} 2$

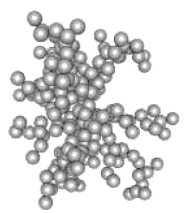

$B \perp 3$ (d)

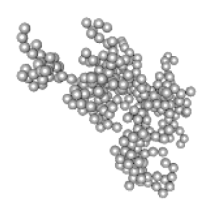

$B\llcorner 4$

Figure 2. Representation of four BC aggregates (not in scale) with increasing number of monomers (see Table 4). In all cases the monomer radius is $20 \mathrm{~nm}$.

\subsection{Morphological characterization of the synthetic aggregates}

In order to ensure that the shape of the synthetic BC aggregates are representative of ambient air samples, we processed the 2-D binary images of the synthetic particles at 50 random orientations. For synthetic aggregates presented in Fig. 2, we have estimated the average $N_{\text {estimated }}$ values ( \pm standard deviation) of $63( \pm 8)$ for BL1, $119( \pm 13)$ for BL2, $179( \pm 12)$ for BL3 and $326( \pm 46)$ for BL4. Morphological descriptors for the cases BL1-BL4 are summarized in Table 4. Aggregates have the same monomer size and similar chain structure but increasing number of monomers.

The accuracy of $N_{\text {estimated values after image processing }}$ are conditional to two main factors: (1) the number of orientations taken for image processing, and (2) the size of the aggregate. In Fig. 3, we present a comparison of the $N_{\text {estimated }}$ values from the 2-D projected images with the actual $N_{\text {true }}$ values used for the generation of the synthetic aggregates. The $N_{\text {estimated }}$ values approximate well $N_{\text {true }}$ values within the uncertainties.

\subsection{Optical properties of bare $\mathrm{BC}$ aggregates}

The spectral dependence of mass extinction, absorption and scattering coefficients (MEC, MAC, MSC) is presented in Fig. 4 for an ensemble of synthetic open-chain-like aggregates, as described in Table 4 (and with a size parameter $\left.X=2 \pi a_{\text {eff }} / \lambda<4.5\right)$. Large differences are found in opti-

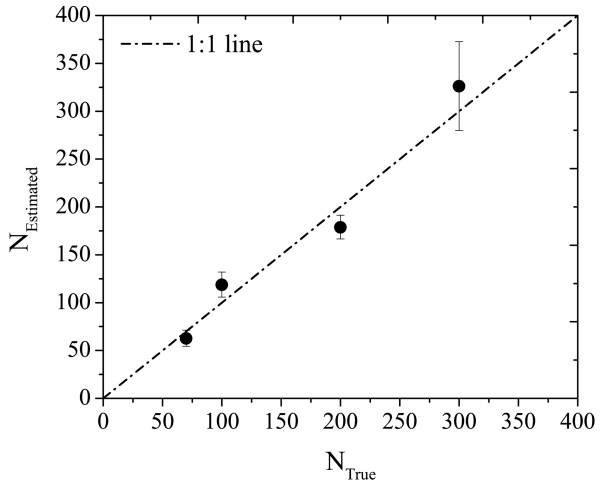

Figure 3. Comparison between the actual monomer $\left(N_{\text {true }}\right)$ number of the synthetic BC aggregates versus the estimated monomer number $\left(N_{\text {estimated }}\right)$ after image processing of 2-D projections of 50 random aggregate orientations, the error bars represent the standard deviation.

cal properties of BC aggregates compared to equivalent volume spherical particles, biases in the numerical simulations and relevance for radiative forcing estimates are discussed in Scarnato et al. (2013) and China et al. (2015).

It is well known that bare/uncoated fresh $\mathrm{BC}$ absorbs more radiation than it scatters (Bond et al., 2013). Therefore, MAC represents the dominant contributor to the MEC. Bond et al. (2013) report BC MAC values larger than $5 \mathrm{~m}^{2} \mathrm{~g}^{-1}$. Predicted values of MEC, MAC and MSC (see Eqs. 7-9) are shown in Fig. 4 for a composite of BC aggregates with sim- 
Table 4. Morphological characterization of synthetic BC particles.

\begin{tabular}{lrrrrrrrr}
\hline Case & $\begin{array}{r}2 r_{\mathrm{m}} \\
{[\mathrm{nm}]}\end{array}$ & $N_{\text {true }}$ & $\begin{array}{r}a_{\mathrm{eff}} \\
{[\mathrm{nm}]}\end{array}$ & $P$ & Convexity & $D_{\mathrm{f}}$ & AR & Roundness \\
\hline BL1 & 40 & 70 & 82 & 0.86 & $0.65 \pm 0.05$ & $1.98 \pm 0.09$ & $1.36 \pm 0.17$ & $0.43 \pm 0.08$ \\
BL2 & 40 & 100 & 100 & 0.92 & $0.66 \pm 0.05$ & $1.95 \pm 0.05$ & $1.46 \pm 0.22$ & $0.38 \pm 0.04$ \\
BL3 & 40 & 200 & 126 & 0.89 & $0.63 \pm 0.04$ & $2.03 \pm 0.05$ & $1.34 \pm 0.16$ & $0.44 \pm 0.05$ \\
BL4 & 40 & 300 & 144 & 0.90 & $0.60 \pm 0.06$ & $1.95 \pm 0.07$ & $1.74 \pm 0.36$ & $0.34 \pm 0.07$ \\
\hline
\end{tabular}
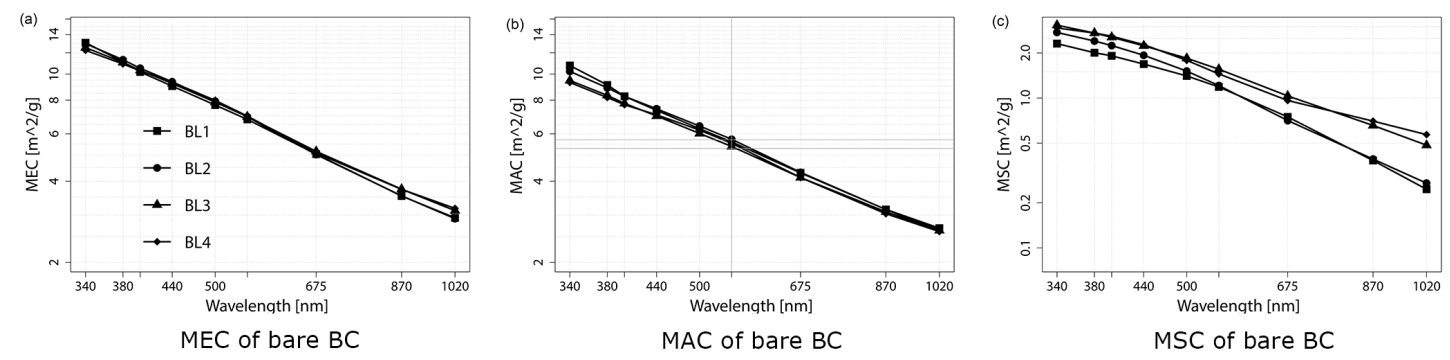

Figure 4. (a) MEC, (b) MAC, and (c) MSC spectral dependency (in log-log scale) for an ensemble of BC aggregates, as described in Tables 1-4. All the computed optical values are averaged over 1000 particle orientations. Dark grey lines underline MAC values at $550 \mathrm{~nm}$. Note that the $y$ scale is different in the three plots.

ilar porosity and monomers size but increasing monomer numbers (see Table 4). MAC values are strongly wavelength dependent (see also Moosmueller et al., 1998, and Lack and Langridge, 2013). At $550 \mathrm{~nm}$ MAC predicted values, using a BC density $(\rho)$ of $1.8 \mathrm{~g} \mathrm{~cm}^{-3}$ (Bond and Bergstrom, 2006), ranging between 5.32 and $5.65 \mathrm{~m}^{2} \mathrm{~g}^{-1}$ and that are not strongly sensitive to the aggregate size. The latter finding is in agreement with the fractal theory by Berry and Percival (1986), which maintains that the mass absorption coefficient should not be a strong function of the size, but rather a strong function of the refractive index and physical shape (as well as mixing) (e.g., Fuller et al., 1999; Liu et al., 2008; Scarnato et al., 2013).

The range of predicted MAC values at $550 \mathrm{~nm}$ is in agreement with field measurements by Clarke et al. (2004) and modeled values by Kahnert (2010a) and Kahnert and Devasthale (2011).

However, several studies (e.g., Bond and Bergstrom, 2006; Adachi et al., 2007; Cross et al., 2010) report larger values. Reasons might be related to different indices of refraction or density values; for instance, the values predicted here are lower than the published values at $550 \mathrm{~nm}$ by Scarnato et al. (2013) because of differences in the adopted refractive indices. At a wavelength of $550 \mathrm{~nm}$, the refractive index by Chang and Charalampopoulos (1990), adopted in these simulations, has lower real and imaginary indices than the value of 1.95-0.79i recommended by Bond and Bergstrom (2006) (see Table 2), which was adopted in simulations by Scarnato et al. (2013). In this study, as in Scarnato et al. (2013), we used a BC $\rho_{1}$ value of $1.8 \mathrm{~g} \mathrm{~cm}^{-3}$. If we use a value of $\rho_{1}$ equal to $1.4 \mathrm{~g} \mathrm{~cm}^{-3}$ and the Chang and Charalampopoulos
(1990) refractive index, we find for the cases BL1-BL4 MAC values at $550 \mathrm{~nm}$ of about $7 \mathrm{~m}^{2} \mathrm{~g}^{-1}$. As a reminder, the OPAC (Optical Properties of Aerosols and Clouds) code uses a density value as low as $1 \mathrm{~g} \mathrm{~cm}^{-3}$ for BC. MSC and SSA values, as shown in Fig. 5, are slightly more sensitive to the aggregates size than to the MAC (see also Scarnato et al., 2013, for the SSA dependence on aggregate compactness). SSA values are lower than those predicted by Scarnato et al. (2013), due as well to the differences in the refractive indices used in the simulations. The SSA magnitude and spectral variation presented in this study are both in agreement with laboratory measurements by Sharma et al. (2013). At $550 \mathrm{~nm}$, SSA shows little variability in cases BL1-BL4 with an average value of $0.19 \pm 0.02$. Just looking at MAC and MEC, one could argue that the implementation of optical properties of bare BC aggregates in chemical transport and radiative transfer models might be greatly facilitated by the fact that some of the properties of $\mathrm{BC}$ aggregates are little sensitive to aggregate size in the UV, Vis and NIR spectra. Such a property would reduce the need for complex parametrizations of BC aggregates' optical properties to accurately model the chain structure, and monomer size of the aggregate (see Liu et al., 2008 , for sensitivity to monomer size). This assumption fails when looking at the asymmetry parameter $(g)$ spectral dependency for the cases BL1-BL4 in Fig. 5b, where $g$ presents a strong sensitivity to the $\mathrm{BC}$ aggregate size in the entire spectral range under study. In Fig. 5, DDSCAT predicts the lowest $g$ values for the BL1 case, intermediate values for the case BL4 and higher values for cases BL2 and BL3. For wavelengths longer than $800 \mathrm{~nm}$ the differences in $g$ values between the cases BL2, BL3 and BL4 are minimized. 

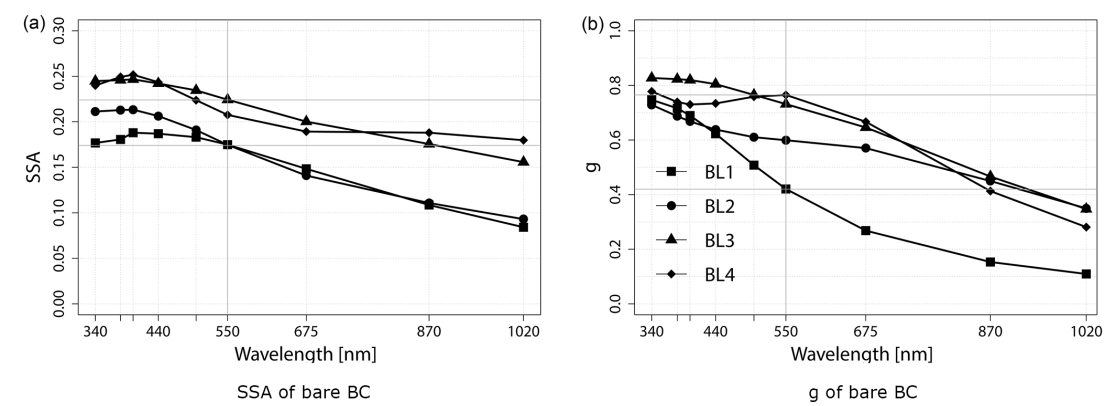

Figure 5. (a) SSA and (b) $g$ spectral dependency for bare BC aggregates (cases BL1-BL4). All the computed optical values are averaged over 1000 particle orientations.

AAE, EAE and SAE values are wavelength dependent (see Table 5 and (Scarnato et al., 2013)). In the spectral range between 340 and $1600 \mathrm{~nm}$, AAE values are consistent with observations and theoretical results with values of approximately 1, while in the spectral range between 400 and $675 \mathrm{~nm}$ AAE values approach 1.2 (in agreement with Lack and Langridge, 2013). The range of values of AAE, EAE and SAE is also fairly consistent with Sharma et al. (2013). For example, we found a SAE average value of $1.79 \pm 0.37$, which is in the range of values reported by Sharma et al. (2013) of $1.61 \pm 0.05$ and by Gyawali et al. (2012) of 1.88.

\subsection{Optical properties of mineral dust}

In all the field campaigns presented here, we have found mineral dust particles with jagged surfaces and irregular shape (see Fig. 1). In particular, in Fig. 1a, c, and d dust particles were found to be silica rich and with a plate-like morphology. We found that the DDSCAT-predicted optical properties have a large variability depending on the modeled dust shape, despite having the same aspect ratio. In Fig. 6, we present the residual of the $Q_{\text {abs,scat,ext }}=C_{\text {abs,scat,ext }} / \pi a_{\text {aeff }}^{2}$ for an ensemble of spheroids (E1, E2, E3, E4, E5) and rectangular prisms $(\mathrm{S} 1, \mathrm{~S} 2, \mathrm{~S} 3, \mathrm{~S} 4, \mathrm{~S} 5)$ with $\mathrm{AR}=1.75$. The difference in the

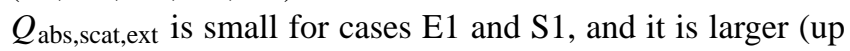
to about $50 \%$ in the $Q_{\text {ext,scat }}$ at $550 \mathrm{~nm}$ ) for larger particle sizes (cases S4 and S5).

The sensitivity of $Q_{\text {abs,scatext }}$ to shape confirms the limited range of applicability of spheroids over different types and sizes of mineral dust aerosols, in agreement with previous modeling studies (Merikallio et al., 2011; Hansell Jr. et al., 2011; Otto et al., 2011). Extended studies on the sensitivity to shape of mineral dust particle optical properties in the UV-NIR range can provide useful constrains on the envelope of values to be expected during measurements in ambient air (i.e., Sokolik and Toon, 1999; Hansell Jr. et al., 2011). From Fig. 6, it is also evident that simplifications, in handling mineral dust particle shape, can generate positive (and at times negative) biases in retrieved AOD (aerosol optical depth) and opacity, when ellipsoids are adopted in the retrieval and aerosol at the site resemble more the synthetic rectangular prisms/modeled particles. The magnitude of the biases are strictly dependent on the wavelength and size of the particles. For example, if aerosols at the site resemble more the rectangular prism than the ellipsoidal shape, large positive biases (up to $50 \%$ ) in retrieved AOD can be expected at $550 \mathrm{~nm}$ for particles with an $a_{\text {eff }}$ between 700 and $1000 \mathrm{~nm}$, as mineral dust particles (cases S4 and S5) modeled as rectangular prisms have a higher $Q_{\text {ext }}$ than ellipsoids (cases E4 and E5). No AOD biases should be expected at $550 \mathrm{~nm}$ depending on the two shape assumptions for particles smaller than $700 \mathrm{~nm}$. Whereas an average AOD bias of $15 \pm 7 \%$ in the shorter wavelength range $(340-500 \mathrm{~nm})$ and $10 \pm 13 \%$ for longer wavelength range $(550-1020 \mathrm{~nm})$ should be expected.

\subsection{Optical properties of $\mathrm{BC}$ aggregates internally mixed}

We have modeled binary internal mixtures of BC aggregates and mineral dust, as visualized in Fig. 7. The BC aggregates are on the surface of the mineral dust particles. Given the plate-like structure of Fig. 1a, c and d, we opted to model mineral dust shape as rectangular prisms. The chosen shape does not cover the whole range of variability encountered in ambient air, but it does for our cases (see Fig. 1, it adds a degree of complexity in the description of mineral dust shape compared to ellipsoids).

In Fig. 8, we present the MAC, MSC, and MEC spectral dependency for three different aerosol types: (1) an ensemble of bare mineral dust particles with aspect ratio of 1.75 and increasing size (cases S1-S5), (2) one bare BC aggregate (case BL2), and (3) internal mixtures of the two types (cases BL2S1-BL2S5, where BL2 is mixed, respectively, with S1, S2, S3, and S5).

Bare mineral dust aerosols (see cases S1-S5 in Fig. 8) have low MAC values compared to bare $\mathrm{BC}$ aggregates (i.e., case BL2 in Fig. 8) in the UV and NIR regions. The MAC values of bare dust are wavelength dependent with larger values predicted in the UV-Vis range. Smaller dust particles have higher MAC. DDSCAT predicts for bare/unpolluted 
Table 5. Summary of optical properties predicted by DDSCAT for bare BC aggregates at $550 \mathrm{~nm}$. AAE and EAE have been calculated in different wavelength ranges: (a) 340-1000 nm, (b) 400-675 nm and (c) 340-1600 nm (spectral range not shown in Fig. 4). MAC and MEC values are provided at $550 \mathrm{~nm}$. MSC values have not been included in the table, as they can be calculated by the difference between MEC and MAC values.

\begin{tabular}{lrrrrrrr}
\hline Case & $\begin{array}{r}\text { AAE } \\
\mathrm{a}(\mathrm{b})(\mathrm{c})\end{array}$ & $\begin{array}{r}\text { EAE } \\
\mathrm{a}(\mathrm{b})(\mathrm{c})\end{array}$ & $\begin{array}{r}\text { SAE } \\
\mathrm{a}(\mathrm{b})(\mathrm{c})\end{array}$ & $\begin{array}{r}\text { MAC(550) } \\
\mathrm{m}^{2} \mathrm{~g}^{-1}\end{array}$ & $\begin{array}{r}\text { MEC(550) } \\
\mathrm{m}^{2} \mathrm{~g}^{-1}\end{array}$ & SSA(550) & $g(550)$ \\
\hline BL1 & $1.26(1.24)(1.04)$ & $1.36(1.33)(1.15)$ & $1.49(1.32)(1.82)$ & 5.60 & 6.80 & 0.17 & 0.42 \\
BL2 & $1.24(1.23)(1.11)$ & $1.38(1.41)(1.26)$ & $1.58(2.20)(2.32)$ & 5.72 & 6.93 & 0.17 & 0.60 \\
BL3 & $1.18(1.21)(1.05)$ & $1.29(1.32)(1.18)$ & $1.33(1.73)(1.90)$ & 5.38 & 6.94 & 0.22 & 0.73 \\
BL4 & $1.18(1.18)(1.04)$ & $1.27(1.35)(1.15)$ & $1.60(1.92)(1.70)$ & 5.53 & 6.98 & 0.20 & 0.76 \\
\hline
\end{tabular}
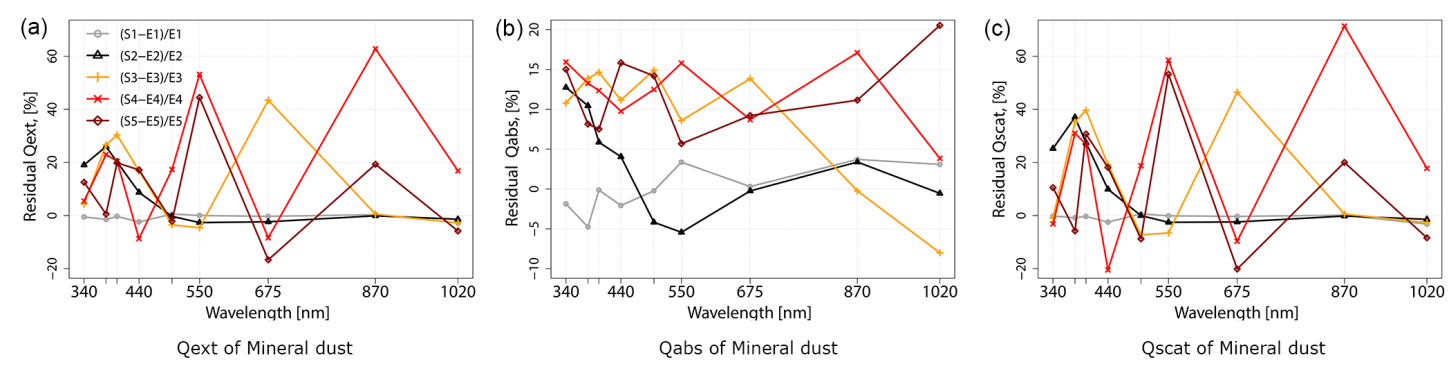

Figure 6. Differences in percentage between extinction, absorption and scattering efficiency for spheroids vs. rectangular prisms.

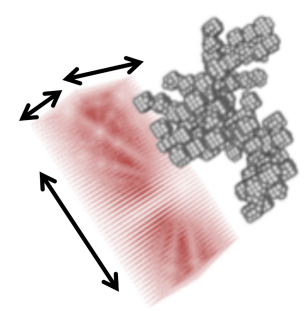

Figure 7. Visual representation of polluted dust, as an internal mixture of $\mathrm{BC}$ and mineral dust. The shape of the particle is represented by an array of coordinates (small dots or spheres) to which is associated a dipole moment. Brown dots represent the dust particle dipoles, while grey, small spheres represent the dipoles of the BC aggregate. The cases BL2S1, BL2S2, BL2S3, and BL2S5 have BL2, respectively, on the surface of S1, S2, S3 and S5. Arrows show that sides of the rectangular prism can vary keeping the aspect ratio constant to a value of 1.75 .

dust at $550 \mathrm{~nm}$ a MAC average value of $0.13 \pm 0.03 \mathrm{~m}^{2} \mathrm{~g}^{-1}$ ( \pm standard deviation).

The internally mixed particles (cases BL2S1-BL2S5, also referred to as polluted dust) have higher MAC values for smaller particles (BL2 has the highest MAC). As expected, DDSCAT predicts higher MAC values for polluted dust than for unpolluted/bare dust, with an average MAC value of $0.26 \pm 0.27 \mathrm{~m}^{2} \mathrm{~g}^{-1}$ at $550 \mathrm{~nm}$.

Furthermore, MSC values of bare mineral dust aerosols have a strong variability with size and wavelength. DDSCAT predicts an average MSC value at $550 \mathrm{~nm}$ of $2.1 \pm 1.9 \mathrm{~m}^{2} \mathrm{~g}^{-1}$ for dust particles ranging in size from 0.18 to $1 \mu \mathrm{m}$. When considering just the accumulation mode, with dust size ranging between 0.5 and $1 \mu \mathrm{m}$, DDSCAT predicts a smaller MSC average value of $0.8 \pm 0.2 \mathrm{~m}^{2} \mathrm{~g}^{-1}$. Fine-mode particles compared to coarse-mode particles have larger MSC values because smaller particles scatter light more efficiently at visible wavelengths. Hand and Malm (2007), after reviewing 60 studies of ground-based observations, report at $550 \mathrm{~nm}$ for the fine-mode dust an average MSC value of $3.3 \pm 0.6 \mathrm{~m}^{2} \mathrm{~g}^{-1}$, while they report in the accumulation mode smaller MSC values of $0.9 \pm 0.8 \mathrm{~m}^{2} \mathrm{~g}^{-1}$, in agreement with our study. The MSC of larger dust particles (cases S3, S4, and S5) does not show a strong spectral dependency, while the opposite is true for small particles (cases S1 and S2); see Fig. 8c. It should be noted that the spectral variability of AOD is used in remote sensing in interpreting aerosol type. For example, mineral dust aerosol is assumed to have a "spectrally flat" AOD, while biomass burning or polluted aerosol usually exhibit a strong wavelength dependence. The spectral dependencies in Fig. 8a demonstrate that small mineral dust aerosol particles and polluted dust have also a strong AOD spectral dependence, those characteristics might be a potential source of classifications of aerosol type, size and amount.

Furthermore, representation of the state of aerosol mixing, whether internal (such cases BL2S $i$ with $i=(1,2,3$, 5)) or external (such as cases BL2 plus Si $i=(1,2,3,5)$ ) might affect the overall optical properties of the aerosols (see Fig. 9). We found that for smaller particles (cases S1, S2, BL2, BL2S1, and BL2S2) external and internal mixtures predict similar values of $C_{\text {abs,scat,ext }}$ in the entire spectral 

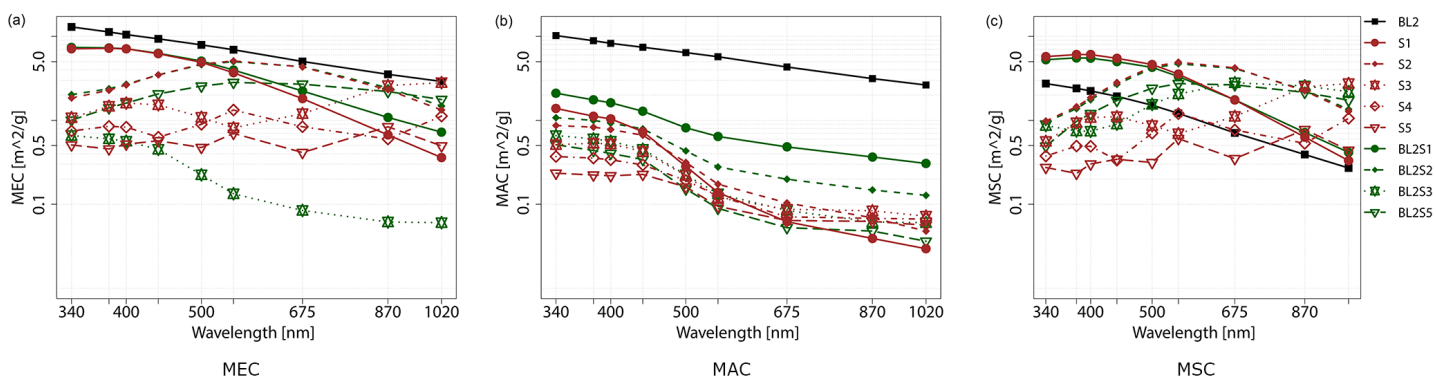

Figure 8. (a) MEC, (b) MAC, and (c) MSC spectral dependency for a BC aggregate (BL2) internally mixed with a mineral dust particle represented as a rectangular prism (BL2S1-BL2S5; see Fig. 7). MEC, MAC, and MSC are normalized by total mass of the internally mixed particle (see Table 2). All the computed optical values are averaged over 1000 particle orientations.
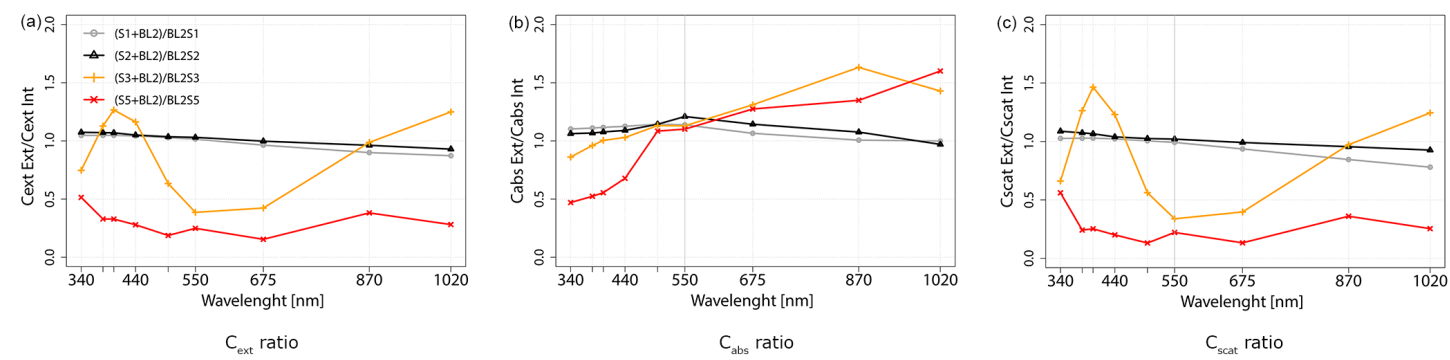

Figure 9. (a) $C_{\mathrm{ext}}$, (b) $C_{\mathrm{abs}}$ and (c) $C_{\mathrm{scat}}$ ratios of an external vs. internal mixture of $\mathrm{BC}$ and mineral dust aerosols.

range, with ratios, respectively, of $1.09 \pm 0.06,0.96 \pm 0.05$ and $1.02 \pm 0.07$.

The latter might be due to the combination of (1) small electromagnetic interactions between the $\mathrm{BC}$ aggregate and the mineral dust particle, due to the small size parameter; and (2) the small difference in size between BC and mineral dust particles (with a mixture / core size ratio smaller than 2.8). However, we found for larger particles (with larger size parameters) with larger differences in $C_{\text {ext, abs, scat val- }}$ ues, depending on the parametrization of the mixing configurations (such as external, cases BL2 + S3, BL2 + S5, BL2S3, and internal BL2S3 and BL2S5). For those cases, simulations using external mixture representations give smaller $C_{\text {abs }}$ values compared to internal mixtures (with average ratio of $0.87 \pm 0.30$ ) for wavelengths shorter than $550 \mathrm{~nm}$, while larger values (average ratio of $1.35 \pm 0.49$ ) for wavelengths larger than $550 \mathrm{~nm}$. Furthermore, $C_{\text {scat }}$ values for external mixtures are smaller than internal mixtures in most of the spectral range studied (and similarly for $C_{\text {ext }}$ values) with average ratios of $0.59 \pm 0.30$ and $0.49 \pm 0.27$ for wavelengths shorter and larger than $550 \mathrm{~nm}$. The internal mixture might lead to larger $C_{\text {scat }}$ (and similarly for $C_{\text {ext }}$ ) values because of larger scattering interactions and electromagnetic coupling between mineral dust and BC, which might lead to an increase in scattering compared to the external mixtures; similar results were found in Scarnato et al. (2013).

The SSA spectral signatures of bare BC (BL2), an ensemble of mineral dust (cases S1-S5), and internal mixtures of the two aerosol components (BL2S1-BL2S5) are shown in Fig. 10. Bare mineral dusts (cases S1-S5) show a typical decrease in the SSA magnitude for wavelengths shorter than $500 \mathrm{~nm}$, with SSA values ranging from 0.85 to 0.96 depending on the size of the dust particle, with smaller values attributed to larger particles. The range of values predicted by DDSCAT, in this study, is in agreement with values of 0.70.97 for Sahara dust reported by Ryder et al. (2013), where the authors attributed variability in measured values to the presence of a significant number of large particles. Furthermore, analyses of the SSA values of Saharan dust from the AERONET reported averages of 0.95 at $0.67 \mu \mathrm{m}$ (Dubovik et al., 2002). SSA values of 0.95-0.99 have been reported during the Saharan Dust Experiment (SHADE) and the Dust Outflow and Deposition to the Ocean (DODO) (Tanre et al., 2003; McConnell et al., 2010; Johnson et al., 2008). Osborne et al. (2008) estimated the SSA for pure dust aerosol during the Dust and Biomass-burning Experiment DABEX, (Haywood et al., 2008) to be consistently high (ranging between 0.98 and 0.99 ).

For wavelengths shorter than $500 \mathrm{~nm}$, small polluted dust particles (BL2S1 and BL2S2) show a stronger decrease in the SSA magnitude compared to unpolluted dust particles (S1 and S2); perturbation of dust optical properties of the same order of magnitude was also found in the Aerosol Characterization Experiment (ACE) field campaign (Clarke et al., 2004). DDSCAT predicts for internally mixed particles larger than $500 \mathrm{~nm}$ (BL2S3-BL2S5) an increase of SSA 


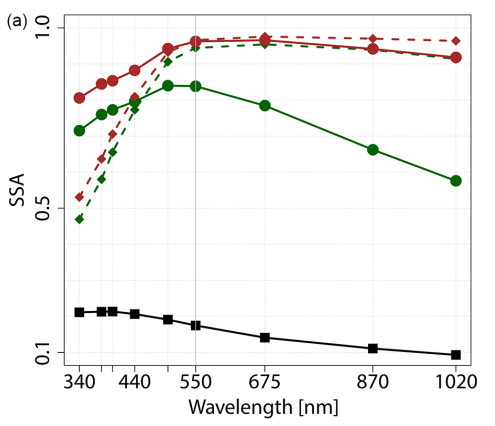

SSA spectral dependency for smaller particles size

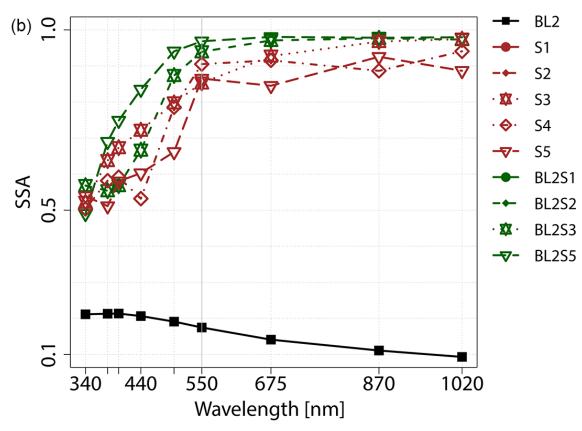

SSA spectral dependency for larger particle size

Figure 10. SSA for different particle sizes in the accumulation mode: (a) finer particles and (b) larger particles.

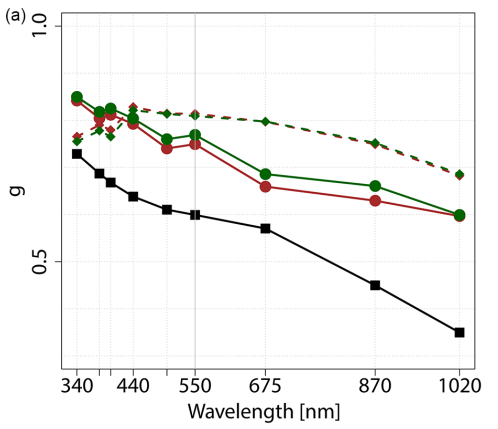

g spectral dependency for smaller dust particles size

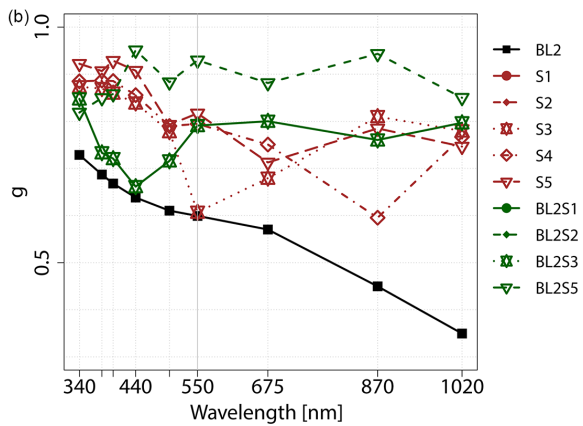

g spectral dependency for larger dust particle size

Figure 11. $g$ for different particle sizes in the accumulation mode: (a) finer particles and (b) larger particles.

at all wavelengths compared to bare dust particles (S3-S5). Such a "cut off" in SSA values is due to the fact that simulations predict for small internally mixed particles (cases BL2S1 and BL2S2), where dust particles are small in size; a steep increase in the absorption and no significant variation in the scattering properties compared to bare mineral dust (S1 and S2). The latter leads to smaller SSA values of internal mixtures compared to bare mineral dust particles. Furthermore, when mineral dust particles are large (cases S3-S5) and therefore the BC mass (case BL2) results comparatively much smaller than the mass of cases S3 and S5) DDSCAT simulations predict a steep increase in the scattering but less in the absorption; therefore, the prevailing scattering vs. absorption for those cases is associated with larger SSA values compared to bare mineral dust.

In an attempt to synthesize the differences between the above-discussed optical properties of bare $\mathrm{BC}$ and internal mixtures, we found that with the increase in size of mineral dust, the absorption increases; however, also the scattering of the internal mixture (cases BL2S1-BL2S5) increases, leading to larger SSA values for internal mixtures compared to bare BC (case BL2) (not shown here, as we provide MAC normalized by the total mass of the particle, not just $\mathrm{BC}$ mass). The increase in the absorption, despite no embedding (no "lens effect"; see also Scarnato et al., 2013) is due to absorption properties of mineral dust.

DDSCAT predicts a wavelength-dependent asymmetry parameter $g$ (see Fig. 11), BC has higher spectral dependency than dust, mostly due to the variation in real part of the $\mathrm{BC}$ refractive index with wavelength. DDSCAT predicts at $550 \mathrm{~nm}$ higher $g$ values for internally mixed polluted dust than bare mineral dust; larger $g$ values are predicted when modeling an external mixture compared to an internal mixture, differences can amount up to about $37 \%$ (see Table 6).

\section{Conclusions}

Microscope images of ambient air aerosol samples collected in various locations of the globe show the occurrence of internal mixtures of BC aggregates and mineral dust aerosols (see also Clarke et al., 2004; Haywood et al., 2008). The aerosol shape/morphology and state of mixing, whether internal or external, can affect the interaction with EMWs and the overall optical properties of the aerosol mixtures, contributing therefore to uncertainty in (1) DRF estimates, (2) validation of chemical transport models with remote sensing measurements, (3) visibility forecasts and (4) spatial and temporal distribution of precipitations and their forecast. 
Table 6. Summary of simulated optical properties for mineral dust and internal mixtures with BC aggregates. AAE and EAE have been calculated in two different wavelength ranges: (a) 340-1020 nm and (b) 400-675 nm.

\begin{tabular}{lrrrrrrrr}
\hline Case & $\begin{array}{r}a_{\text {eff }} \\
\mathrm{nm}]\end{array}$ & $\begin{array}{r}\text { AAE } \\
\mathrm{a}(\mathrm{b})\end{array}$ & $\begin{array}{r}\text { EAE } \\
\mathrm{a}(\mathrm{b})\end{array}$ & $\begin{array}{r}\text { SEA } \\
\mathrm{a}(\mathrm{b})\end{array}$ & $\begin{array}{r}\text { MAC(550) } \\
\mathrm{m}^{2} \mathrm{~g}^{-1}\end{array}$ & $\begin{array}{r}\text { MEC(550) } \\
\mathrm{m}^{2} \mathrm{~g}^{-1}\end{array}$ & SSA(550 nm) & $g(550 \mathrm{~nm})$ \\
\hline S1 & 180 & $3.92(5.68)$ & $2.8(2.62)$ & $2.75(2.37)$ & 0.14 & 3.70 & 0.96 & 0.75 \\
S2 & 284 & $2.90(4.16)$ & $0.22(0.95)$ & $0.25(1.56)$ & 0.17 & 5.10 & 0.96 & 0.81 \\
S3 & 500 & $2.15(3.70)$ & $0.65(0.80)$ & $1.17(0.18)$ & 0.12 & 0.82 & 0.85 & 0.60 \\
S4 & 700 & $1.89(3.13)$ & $0.10(0.47)$ & $0.69(1.5)$ & 0.13 & 1.32 & 0.90 & 0.79 \\
S5 & 1000 & $1.53(2.60)$ & $0.18(0.26)$ & $0.74(0.60)$ & 0.10 & 0.70 & 0.86 & 0.81 \\
BL2S1 & 190 & $1.84(2.39)$ & $2.20(2.23)$ & $2.46(2.19)$ & 0.64 & 3.97 & 0.84 & 0.77 \\
BL2S2 & 289 & $2.00(2.48)$ & $1.08(0.14)$ & $0.27(1.63)$ & 0.27 & 5.00 & 0.94 & 0.81 \\
BL2S3 & 503 & $2.10(3.17)$ & $0.19(0.93)$ & $0.34(2.68)$ & 0.13 & 2.19 & 0.94 & 0.79 \\
BL2S5 & 1010 & $2.68(4.20)$ & $0.45(0.97)$ & $0.92(1.48)$ & 0.09 & 2.82 & 0.96 & 0.88 \\
\hline
\end{tabular}

In this study, we carried out numerical simulations to investigate the sensitivity of climate-relevant aerosol optical properties to various approximations on aerosol size, shape and state of mixing and draw benchmark considerations for climate studies and remote sensing applications. Based on aerosol samples collected in Mexico, England, USA (California) and Portugal, we have observationally constrained morphology and mixing and modeled optical properties accordingly, of three different types of aerosols: (1) bare BC aggregates, (2) bare mineral dust, and (3) an internal mixture of $\mathrm{BC}$ and dust particles, also referred to as polluted dust.

Optical properties including MAC, MEC, MSC, AAE, EAE, SSA and $g$ were predicted over the spectral range between 340 and $1020 \mathrm{~nm}$ using DDSCAT, which applies the discrete dipole approximation (DDA). Specific wavelengths have been selected to match the AERONET nominal channels.

Key results for bare $\mathrm{BC}$ aggregates include (i) a weak MAC dependency on the aggregate size, but stronger MAC dependency on the refractive index, in agreement with Berry and Percival (1986), Liu et al. (2008) and Scarnato et al. (2013); (ii) a strong $g$ dependency on aggregate size; (iii) consistency between DDSCAT-predicted and observed values of AAE, EAE, SAE (e.g., Lack and Langridge, 2013) and SSA (and its spectral variability) (Sharma et al., 2013).

Key results for bare mineral dust aerosol include (i) a strong sensitivity of dust optical properties to shape (DDSCAT predicts at $550 \mathrm{~nm}$ an average difference between spheroids and prisms of about $20 \%$ for MEC and MSC, while of about $5 \%$ for MAC); (ii) a consistency between DDSCAT-predicted and observed values of MAC, MSC and SSA reported by Hand and Malm (2007); and (iii) a typical decrease in the SSA magnitude for wavelengths shorter than $500 \mathrm{~nm}$ (also found to be characteristic of organics and the aerosol mixtures of sodium chloride and BC; see also Scarnato et al., 2013; Russell et al., 2010).

Key results for polluted mineral dust, an internal mixture of $\mathrm{BC}$ and mineral dust, include (i) a strong decrease in MAC values with the increase in dust particle size (case
BL2S1 presents largest values), while the opposite for SSA values. (ii) A decrease in the SSA magnitude compared to bare dust for smaller dust particle sizes (cases BL2S1 and BL2S2) in agreement with Clarke et al. (2004). Furthermore, (iii) the strong differences in predicted magnitude and spectral dependence of $C_{\text {abs,scat,ext }}$ when mixing a BC aggregate (case BL2) externally or internally with large mineral dust particles (cases S3, S5, BL2S3, and BL2S5).

With this study, we demonstrated the importance of (i) characterizing and defining microphysical properties, such as morphology/shape and mixing of different aerosol types collected in ambient air, (ii) estimating optical properties accordingly to observations, and (iii) defining eventual benchmark errors due to use of approximations in shape and mixing. More studies are needed to assess the abundance of polluted dust particles in the atmosphere. In fact, the occurrence of such configuration is currently highly uncertain and might strongly depend on source and transport regions. Accounting for changes in optical properties, induced by mixing as well as by the abundance of mixed particles, might be critical not only for calculating the relevance of such particles on regional radiative forcing but also to understand biases in remote sensing techniques and to explore the potential of such techniques in remotely detected mixed particle cases.

Acknowledgements. The work in this paper has been funded by the Research Initiation Program at the Naval Postgraduate school. Some of the work discussed in this paper was funded through the following grants: NASA (grant NNX13AN68H), NSF (grant AGS-1110059), DOE (grants DE-SC0006941 and DE-SC0010019). S. China and C. Mazzoleni would also like to acknowledge the contribution of several collaborators while collecting aerosol samples in several field campaigns and utilized here. Scarnato would like to acknowledge Denis Richard for providing the aggregation code, and Sanaz Vahidinia for building a first version of the internal mixing code.

Edited by: M. C. Facchini 


\section{References}

Adachi, K. and Buseck, P. R.: Changes of ns-soot mixing states and shapes in an urban area during CalNex, J. Geophys. Res.-Atmos., 118, 3723-3730, doi:10.1002/jgrd.50321, 2013.

Adachi, K., Chung, S. H., Friedrich, H., and Buseck, P. R.: Fractal parameters of individual soot particles determined using electron tomography: Implications for optical properties, J. Geophys. Res.-Atmos., 112, D14202, doi:10.1029/2006JD008296, 2007.

Adachi, K., Chung, S., and Buseck, P.: Shapes of soot aerosol particles and implications for their effects on climate, J. Geophys. Res., 115, D15206, doi:10.1029/2009JD012868, 2010.

Berry, M. and Percival, I.: Optics of fractal clusters such as smoke, Opt. Acta, 33, 577-591, 1986.

Bond, T. C. and Bergstrom, R.: Light Absorption by Carbonaceous Particles: An Investigative Review, Aerosol Sci. Technol., 40, 27-67, 2006.

Bond, T. C., Doherty, S. J., Fahey, D. W., Forster, P. M., Berntsen, T., DeAngelo, B. J., Flanner, M. G., Ghan, S., Kärcher, B., Koch, D., Kinne, S., Kondo, Y., Quinn, P. K., Sarofim, M. C., Schultz, M. G., Schulz, M., Venkataraman, C., Zhang, H., Zhang, S., Bellouin, N., Guttikunda, S. K., Hopke, P. K., Jacobson, M. Z., Kaiser, J. W., Klimont, Z., Lohmann, U., Schwarz, J. P., Shindell, D., Storelvmo, T., Warren, S. G., and Zender, C. S.: Bounding the role of black carbon in the climate system: A scientific assessment, J. Geophys. Res.-Atmos., 118, 5380-5552, doi:10.1002/jgrd.50171, 2013.

Bueno, P. A., Havey, D., Mulholland, G., Hodges, J., Gillis, K., Dickerson, R., and Zachariah, M.: Photoacoustic Measurements of Amplification of the Absorption Cross Section for Coated Soot Aerosols, Aerosol Sci. Technol., 45, 1217-1230, doi:10.1080/02786826.2011.587477, 2011

Cappa, C. D., Onasch, T., Massoli, P., Worsnop, D. R., Bates, T. S., Cross, E. S., Davidovits, P., Hakala, J., Hayden, K. L., Jobson, B. T., Kolesar, K. R., Lack, D. A., Lerner, B. M., Li, S., Mellon, D., Nuaaman, I., Olfert, J. S., Petaejae, T., Quinn, P. K., Song, C., Subramanian, R., Williams, E., and Zaveri, R. A.: Radiative Absorption Enhancements Due to the Mixing State of Atmospheric Black Carbon, Science, 337, 1078-1081, doi:10.1126/science.1223447, 2012a.

Cappa, C. D., Onasch, T. B., Massoli, P., Worsnop, D. R., Bates, T. S., Cross, E. S., Davidovits, P., Hakala, J., Hayden, K. L., Jobson, B. T., Kolesar, K. R., Lack, D. A., Lerner, B. M., Li, S.-M., Mellon, D., Nuaaman, I., Olfert, J. S., Petäjä, T., Quinn, P. K., Song, C., Subramanian, R., Williams, E. J., and Zaveri, R. A.: Radiative Absorption Enhancements Due to the Mixing State of Atmospheric Black Carbon, Science, 337, 1078-1081, 2012b.

Chang, H. and Charalampopoulos, T. T.: Determination of the wavelength dependence of refractive indices of flame soot, Proc. R. Soc. London, 1, 577-591, 1990.

Chester, R., Elderfield, H., Griffin, J. J., Johnson, L. R., and Padgham, R. C.: Eolian dust along the easter margins, Mar. Geol., 13, 91-106, 1972.

China, S., Mazzoleni, C., Gorkowski, K., Aiken, A. C., and Dubey, M. K.: Morphology and mixing state of individual freshly emitted wildfire carbonaceous particles, Nat. Commun., 4, 2122, doi:10.1038/ncomms3122, 2013.

China, S., Salvadori, N., and Mazzoleni, C.: Effect of Traffic and Driving Characteristics on Morphology of Atmospheric Soot
Particles at Freeway On-Ramps, Environ. Sci. Technol., 48, 3128-3135, doi:10.1021/es405178n, 2014.

China, S., Scarnato, B., Owen, R. C., Zhang, B., Ampadu, M. T., Kumar, S., Dzepina, K., Dziobak, M. P., Fialho, P., Perlinger, J. A., Hueber, J., Helmig, D., Mazzoleni, L. R., and Mazzoleni, C.: Morphology and mixing state of aged soot particles at a remote marine free troposphere site: Implications for optical properties, Geophys. Res. Lett., 42, 1243-1250, 2015.

Chou, C., Formenti, P., Maille, M., Ausset, P., and Helas, G.: Size distribution, shape, and composition of mineral dust aerosols collected during the African Monsoon Multidisciplinary Analysis Special Observation Period 0: dust and biomass-burning experiment field campaign in Niger, J. Geophys. Res., 113, D00C10, doi:10.1029/2008JD009897, 2006.

Chylek, P. and Wong, J.: Effect of absorbing aerosols on global radiation budget, Geophys. Res. Lett., 22, 929-931, doi:10.1029/95GL00800, 1995.

Clarke, A. D., Shinozuka, Y., Kapustin, V. N., Howell, S., Huebert, B., Doherty, S., Anderson, T., Covert, D., Anderson, J., Hua, X., Moore, K. G., McNaughton, C., Carmichael, G., and Weber, R.: Size distributions and mixtures of dust and black carbon aerosol in Asian outflow: Physiochemistry and optical properties, J. Geophys. Res.-Atmos., 109, D15S09, doi:10.1029/2003JD004378, 2004.

Cross, E. S., Onasch, T. B., Ahern, A., Wrobel, W., Slowik, J. G., Olfert, J., Lack, D. A., Massoli, P., Cappa, C. D., Schwarz, J. P., Spackman, J. R., Fahey, D. W., Sedlacek, A., Trimborn, A., Jayne, J. T., Freedman, A., Williams, L. R., Ng, N. L., Mazzoleni, C., Dubey, M., Brem, B., Kok, G. S. R., Freitag, S., Clarke, A., Thornhill, D., Marr, L. C., Kolb, C. E., Worsnop, D. R., and Davidovits, P.: Soot Particle Studies - Instrument Inter-Comparison - Project Overview, Aerosol Sci. Technol., 44, 592-611, doi:10.1080/02786826.2010.482113, 2010.

Deuze, J., Breon, F., Devaux, C., Goloub, P., Herman, H., Lafrance, B., Maignan, F., Marchand, A., Nadal, F., Perry, G., and Tanre, D.: Remote sensing of aerosols over land surfaces from POLDER-ADEOS-1 polarized measurements, J. Geophys. Res., 106, 4913-4926, doi:10.1029/2000JD900364, 2001.

Draine, B. and Flatau: Discrete dipole approximation for scattering calculations, J. Opt. Soc. Am. A, 11, 1491-1499, 1994.

Draine, B. and Flatau, P. J.: User Guide to the Discrete Dipole Approximation Code DDSCAT 7.1, Cornell University Library, 2010.

Dubovik, O., Holben, B. N., Lapyonok, T., Sinyuk, A., Mishchenko, M. I., Yang, P., and Slutsker, I.: Non-spherical aerosol retrieval method employing light scattering by spheroids, Geophys. Res. Lett., 29, 541-544, doi:10.1029/2001GL014506, 2002.

Dubovik, O., Sinyuk, A., Lapyonok, T., and Holben, B. N., and Mishchenko, M.: Application of spheroid models to account for aerosol particle nonsphericity in remote sensing of desert dust, $\mathrm{J}$. Geophys. Res., 111, D11208, doi:10.1029/2005JD006619, 2006.

Durkee, P. A., Nielsen, K. E., Smith, P. J., Russell, P. B., Schmid, B., Livingston, J. M., Holben, B. N., Tomasi, C., Vitale, V., Collins, D., Flagan, R. C., Seinfeld, J. H., Noone, K. J., Öström, E., Gassó, S., Hegg, D., Russell, L. M., Bates, T. S., and Quinn, P. K.: Regional aerosol optical depth characteristics from satellite observations: ACE-1, TARFOX and ACE-2 results, Tellus B, 52, 484-497, doi:10.1034/j.1600-0889.2000.00040.x, 2000 
Dzepina, K., Mazzoleni, C., Fialho, P., China, S., Zhang, B., Owen, R. C., Helmig, D., Hueber, J., Kumar, S., Perlinger, J. A., Kramer, L. J., Dziobak, M. P., Ampadu, M. T., Olsen, S., Wuebbles, D. J., and Mazzoleni, L. R.: Molecular characterization of free tropospheric aerosol collected at the Pico Mountain Observatory: a case study with a long-range transported biomass burning plume, Atmos. Chem. Phys., 15, 5047-5068, doi:10.5194/acp-15-50472015, 2015.

Fuller, K. A., Malm, W. C., and Kreidenweis, S. M.: Effects of mixing on extinction by carbonaceous particles, J. Geophys. Res., 104, 15941-15954, 1999.

Gyawali, M., Arnott, W. P., Zaveri, R. A., Song, C., Moosmüller, H., Liu, L., Mishchenko, M. I., Chen, L.-W. A., Green, M. C., Watson, J. G., and Chow, J. C.: Photoacoustic optical properties at UV, VIS, and near IR wavelengths for laboratory generated and winter time ambient urban aerosols, Atmos. Chem. Phys., 12, 2587-2601, doi:10.5194/acp-12-2587-2012, 2012.

Hand, J. L. and Malm, W. C.: Review of aerosol mass scattering efficiencies from ground-based measurements since 1990, J. Geophys. Res.-Atmos., 112, D16203, doi:10.1029/2007JD008484, 2007.

Hansell Jr., R. A., Reid, J. S., Tsay, S. C., Roush, T. L., and Kalashnikova, O. V.: A sensitivity study on the effects of particle chemistry, asphericity and size on the mass extinction efficiency of mineral dust in the earth's atmosphere: from the near to thermal IR, Atmos. Chem. Phys., 11, 1527-1547, doi:10.5194/acp-111527-2011, 2011.

Hasekamp, O., Litvinov, P., and Butz, A.: Aerosol properties over the ocean from PARASOL multiangle photopolarimetric measurements, J. Geophys. Res., 116, D14204, doi:10.1029/2010JD015469, 2011.

Haywood, J. M., Pelon, J., Formenti, P., Bharmal, N., Brooks, M., Capes, G., Chazette, P., Chou, C., Christopher, S., Coe, H., Cuesta, J., Derimian, Y., Desboeufs, K., Greed, G., Harrison, M., Heese, B., Highwood, E. J., Johnson, B., Mallet, M., Marticorena, B., Marsham, J., Milton, S., Myhre, G., Osborne, S. R., Parker, D. J., Rajot, J.-L., Schulz, M., Slingo, A., Tanré, D., and Tulet, P.: Overview of the Dust and Biomass-burning Experiment and African Monsoon Multidisciplinary Analysis Special Observing Period-0, J. Geophys. Res.-Atmos., 113, D00C17, doi:10.1029/2008JD010077, 2008.

Honrath, R., Owen, R. C., Val Martin, M., Reid, J., Lapina, K., Fialho, P., Dziobak, M. P., Kleissl, J., and Westphal, D.: Regional and hemispheric impacts of anthropogenic and biomass burning emissions on summertime $\mathrm{CO}$ and $\mathrm{O}_{3}$ in the North Atlantic lower free troposphere, J. Geophys. Res.-Atmos., 109, D24310, doi:10.1029/2004JD005147, 2004.

Jacobson, M.: Strong radiative heating due to mixing state of black carbon in atmospheric aerosol, Letters to Nature, 409, 695-697, doi:10.1038/35055518, 2001.

Jacobson, M. Z.: Effects of biomass burning on climate, accounting for heat and moisture fluxes, black and brown carbon, and cloud absorption effects, J. Geophys. Res.-Atmos., 119, 89809002, doi:10.1002/2014JD021861, 2014.

Johnson, B. T., Osborne, S. R., Haywood, J. M., and Harrison, M. A. J.: Aircraft measurements of biomass burning aerosol over West Africa during DABEX, J. Geophys. Res.-Atmos., 113, D00C06, doi:10.1029/2007JD009451, 2008.
Kahnert, M.: On the Discrepancy between Modeled and Measured Mass Absorption Cross Sections of Light Absorbing Carbon Aerosols, Aerosol Sci. Technol., 44, 453-460, doi:10.1080/02786821003733834, 2010a.

Kahnert, M.: Numerically exact computation of the optical properties of light absorbing carbon aggregates for wavelength of $200 \mathrm{~nm}-12.2 \mu \mathrm{m}$, Atmos. Chem. Phys., 10, 8319-8329, doi:10.5194/acp-10-8319-2010, 2010b.

Kahnert, M. and Devasthale, A.: Black carbon fractal morphology and short-wave radiative impact: a modelling study, Atmos. Chem. Phys., 11, 11745-11759, doi:10.5194/acp-11-117452011, 2011.

Kahnert, M., Nousiainen, T., Lindqvist, H., and Ebert, M.: Optical properties of light absorbing carbon aggregates mixed with sulfate: assessment of different model geometries for climate forcing calculations, Opt. Express, 20, 10042-10058, doi:10.1364/OE.20.010042, 2012.

Kalashnikova, O. V., Garay, M. J., Martonchik, J. V., and Diner, D. J.: MISR Dark Water aerosol retrievals: operational algorithm sensitivity to particle non-sphericity, Atmos. Meas. Tech., 6, 2131-2154, doi:10.5194/amt-6-2131-2013, 2013.

Kandler, K., Schutz, L., Deutscher, C., Ebert, M., and Hofmann, H.: Size distribution, mass concentration, chemical and mineralogical composition, and derived optical parameters of the boundary layer aerosol at Tinfou, Morocco, during SAMUM, Tellus B, 61, 32-50, 2006.

Kim, D., Wang, C., Ekman, A. M. L., Barth, M. C., and Rasch, P. J.: Distribution and direct radiative forcing of carbonaceous and sulfate aerosols in an interactive size-resolving aerosol-climate model, J. Geophys. Res.-Atmos., 113, D16309, doi:10.1029/2007JD009756, 2008.

Klingmüller, K., Steil, B., Brühl, C., Tost, H., and Lelieveld, J.: Sensitivity of aerosol radiative effects to different mixing assumptions in the AEROPT 1.0 submodel of the EMAC atmosphericchemistry-climate model, Geosci. Model Dev., 7, 2503-2516, doi:10.5194/gmd-7-2503-2014, 2014.

Koch, D., Schulz, M., Kinne, S., McNaughton, C., Spackman, J. R., Balkanski, Y., Bauer, S., Berntsen, T., Bond, T. C., Boucher, O., Chin, M., Clarke, A., De Luca, N., Dentener, F., Diehl, T., Dubovik, O., Easter, R., Fahey, D. W., Feichter, J., Fillmore, D., Freitag, S., Ghan, S., Ginoux, P., Gong, S., Horowitz, L., Iversen, T., Kirkevåg, A., Klimont, Z., Kondo, Y., Krol, M., Liu, X., Miller, R., Montanaro, V., Moteki, N., Myhre, G., Penner, J. E., Perlwitz, J., Pitari, G., Reddy, S., Sahu, L., Sakamoto, H., Schuster, G., Schwarz, J. P., Seland, Ø., Stier, P., Takegawa, N., Takemura, T., Textor, C., van Aardenne, J. A., and Zhao, Y.: Evaluation of black carbon estimations in global aerosol models, Atmos. Chem. Phys., 9, 9001-9026, doi:10.5194/acp-9-9001-2009, 2009.

Lack, D. A. and Langridge, J. M.: On the attribution of black and brown carbon light absorption using the Ångström exponent, Atmos. Chem. Phys. Discuss., 13, 15493-15515, doi:10.5194/acpd-13-15493-2013, 2013.

Lau, K. and Kim, K.: Observational relationships between aerosol and Asian monsoon rainfall, and circulation, Geophys. Res. Lett., 33, L21810, doi:10.1029/2006GL027546, 2006.

Liu, L., Mishchenko, M. I., and Arnott, W. P.: A study of radiative properties of fractal soot aggregates using the superposition Tmatrix method, J. Quant. Spectrosc. Ra., 109, 2656-663, 2008. 
McConnell, C. L., Formenti, P., Highwood, E. J., and Harrison, M. A. J.: Using aircraft measurements to determine the refractive index of Saharan dust during the DODO Experiments, Atmos. Chem. Phys., 10, 3081-3098, doi:10.5194/acp-10-30812010, 2010.

Merikallio, S., Lindqvist, H., Nousiainen, T., and Kahnert, M.: Modelling light scattering by mineral dust using spheroids: assessment of applicability, Atmos. Chem. Phys., 11, 5347-5363, doi:10.5194/acp-11-5347-2011, 2011.

Mishra, S. K., Tripathi, S. N., Aggarwal, S., and Arola, A.: Optical properties of accumulation mode, polluted mineral dust: effects of particle shape, hematite content and semiexternal mixing with carbonaceous species, Tellus B, 64, 18536, doi:10.3402/tellusb.v64i0.18536, 2012.

Moosmueller, H., Arnott, W. P., Rogers, C. F., Chow, J. C., Frazier, C. A., Sherman, L. E., and Dietrich, D. L.: Photoacoustic and filter measurements related to aerosol light absorption during the Northern Front Range Air Quality Study (Colorado 1996/1997), J. Geophys. Res.-Atmos., 103, 28149-28157, doi:10.1029/98JD02618, 1998.

Nousiainen, T.: Optical modeling of mineral dust particles: A review, J. Quant. Spectrosc. Ra., 110, 1261-1279, 2009.

Oh, C. and Sorensen, C.: The Effect of Overlap between Monomers on the Determination of Fractal Cluster Morphology, J. Colloid Interf. Sci., 193, 17-25, doi:10.1006/jcis.1997.5046, 1997.

Osborne, S. R., Johnson, B. T., Haywood, J. M., Baran, A. J., Harrison, M. A. J., and McConnell, C. L.: Physical and optical properties of mineral dust aerosol during the Dust and Biomassburning Experiment, J. Geophys. Res.-Atmos., 113, D00C03, doi:10.1029/2007JD009551, 2008.

Otto, S., Trautmann, T., and Wendisch, M.: On realistic size equivalence and shape of spheroidal Saharan mineral dust particles applied in solar and thermal radiative transfer calculations, Atmos. Chem. Phys., 11, 4469-4490, doi:10.5194/acp-11-44692011, 2011.

Prospero, J. M., Glaccum, R. A., and Nees, R. T.: Atmospheric transport of soil dust from Africa to South America, Nature, 289, 570-572, 1981.

Reale, O., Lau, K. M., and da Silva, A.: Impact of interactive aerosol on the african easterly jet in the nasa geos-5 global forecasting system, Weather Forecast., 26, 504-519, doi:10.1175/WAF-D10-05025.1, 2011.

Reid, E. A., Reid, J. S., Meier, M. M., Dunlap, M. R., and Cliff, S. S.: Characterization of African dust transported to Puerto Rico by individual particle and size segregated bulk analysis, J. Geophys. Res., 108, 8591, doi:10.1029/2002JD002935, 2003.

Richard, D., Glenar, D., Stubbs, T., Davis, S., and Colaprete, A.: Light scattering by complex particles in the Moon's exosphere: Toward a taxonomy of models for the realistic simulation of the scattering behavior of lunar dust, Planet. Space Sci., 59, 1804 1814, doi:10.1016/j.pss.2011.01.003, 2011.

Richard, D. T. and Davis, S. S.: Lunar dust characterization by polarimetric signature, Astron. Astrophys., 483, 643-649, doi:10.1051/0004-6361:20079108, 2008.

Russell, P. and Heintzenburg, J.: An overview of the ACE-2 clear sky column closure experiment, Tellus, 52, 463-483, 2000.

Russell, P. B., Bergstrom, R. W., Shinozuka, Y., Clarke, A. D., DeCarlo, P. F., Jimenez, J. L., Livingston, J. M., Redemann, J., Dubovik, O., and Strawa, A.: Absorption Angstrom Exponent in
AERONET and related data as an indicator of aerosol composition, Atmos. Chem. Phys., 10, 1155-1169, doi:10.5194/acp-101155-2010, 2010.

Ryder, C. L., Highwood, E. J., Rosenberg, P. D., Trembath, J., Brooke, J. K., Bart, M., Dean, A., Crosier, J., Dorsey, J., Brindley, H., Banks, J., Marsham, J. H., McQuaid, J. B., Sodemann, H., and Washington, R.: Optical properties of Saharan dust aerosol and contribution from the coarse mode as measured during the Fennec 2011 aircraft campaign, Atmos. Chem. Phys., 13, 303325, doi:10.5194/acp-13-303-2013, 2013.

Samset, B. H., Myhre, G., Schulz, M., Balkanski, Y., Bauer, S., Berntsen, T. K., Bian, H., Bellouin, N., Diehl, T., Easter, R. C., Ghan, S. J., Iversen, T., Kinne, S., Kirkevåg, A., Lamarque, J.F., Lin, G., Liu, X., Penner, J. E., Seland, Ø., Skeie, R. B., Stier, P., Takemura, T., Tsigaridis, K., and Zhang, K.: Black carbon vertical profiles strongly affect its radiative forcing uncertainty, Atmos. Chem. Phys., 13, 2423-2434, doi:10.5194/acp-13-24232013, 2013.

Samson, R. J., Mulholland, G. W., and Gentry, J. W.: Structural analysis of soot agglomerates, Langmuir, 3, 272-281, doi:10.1021/la00074a022, 1987.

Scarnato, B. V., Vahidinia, S., Richard, D. T., and Kirchstetter, T. W.: Effects of internal mixing and aggregate morphology on optical properties of black carbon using a discrete dipole approximation model, Atmos. Chem. Phys., 13, 5089-5101, doi:10.5194/acp-13-5089-2013, 2013.

Sharma, N., Arnold, I. J., Moosmüller, H., Arnott, W. P., and Mazzoleni, C.: Photoacoustic and nephelometric spectroscopy of aerosol optical properties with a supercontinuum light source, Atmos. Meas. Tech., 6, 3501-3513, doi:10.5194/amt-6-35012013, 2013.

Shen, Y., Draine, B. T., and Eric, T. J.: Modeling Porous Dust Grains with Ballistic Aggregates. I. Geometry and Optical Properties, Astrophys. J., 689, 260, doi:10.1086/592765, 2008.

Sokolik, I. N. and Toon, O. B.: Incorporation of mineralogical composition into models of the radiative properties of mineral aerosol from UV to IR wavelengths, J. Geophys. Res.-Atmos., 104, 9423-9444, doi:10.1029/1998JD200048, 1999.

Sokolik, I. N., Winker, D. M., Bergametti, G., Gillette, D. A., Carmichael, G., Kaufman, Y. J., Gomes, L., Schuetz, L., and Penner, J. E.: Introduction to special section: Outstanding problems in quantifying the radiative impacts of mineral dust, J. Geophys. Res.-Atmos., 106, 18015-18027, doi:10.1029/2000JD900498, 2001.

Tanre, D., Haywood, J., Pelon, J., Leon, J. F., Chatenet, B., Formenti, P., Francis, P., Goloub, P., Highwood, E. J., and Myhre, G.: Measurement and modeling of the Saharan dust radiative impact: Overview of the Saharan Dust Experiment (SHADE), J. Geophys. Res.-Atmos., 108, 8574, doi:10.1029/2002JD003273, 2003.

Usher, C. R., Michel, A. E., and Grassian, V. H.: Reactions on Mineral Dust, Chem. Rev., 103, 4883-4940, doi:10.1021/cr020657y, 2003.

Wagner, R., Ajtai, T., Kandler, K., Lieke, K., Linke, C., Müller, T., Schnaiter, M., and Vragel, M.: Complex refractive indices of Saharan dust samples at visible and near UV wavelengths: a laboratory study, Atmos. Chem. Phys., 12, 2491-2512, doi:10.5194/acp-12-2491-2012, 2012. 
Xue, H., Khalizov, A. F., Wang, L., Zheng, J., and Zhang, R.: Effects of dicarboxylic acid coating on the optical properties of soot, Chem. Chem. Phys., 11, 7869-7875, doi:10.1039/B904129J, 2009.

Yoshida, M., Haywood, J. M., Yokohata, T., Murakami, H., and Nakajima, T.: Spatial distribution of dust's optical properties over the Sahara and Asia inferred from Moderate Resolution Imaging Spectroradiometer, Atmos. Chem. Phys., 13, 10827-10845, doi:10.5194/acp-13-10827-2013, 2013.

Zaveri, R. A., Shaw, W. J., Cziczo, D. J., Schmid, B., Ferrare, R. A., Alexander, M. L., Alexandrov, M., Alvarez, R. J., Arnott, W. P., Atkinson, D. B., Baidar, S., Banta, R. M., Barnard, J. C., Beranek, J., Berg, L. K., Brechtel, F., Brewer, W. A., Cahill, J. F., Cairns, B., Cappa, C. D., Chand, D., China, S., Comstock, J. M., Dubey, M. K., Easter, R. C., Erickson, M. H., Fast, J. D., Floerchinger, C., Flowers, B. A., Fortner, E., Gaffney, J. S., Gilles, M. K., Gorkowski, K., Gustafson, W. I., Gyawali, M., Hair, J., Hardesty, R. M., Harworth, J. W., Herndon, S., Hiranuma, N., Hostetler, C., Hubbe, J. M., Jayne, J. T., Jeong, H., Jobson, B. T., Kassianov, E. I., Kleinman, L. I., Kluzek, C., Knighton, B., Kolesar, K. R., Kuang, C., Kubátová, A., Langford, A. O., Laskin, A., Laulainen, N., Marchbanks, R. D., Mazzoleni, C., Mei, F., Moffet, R. C., Nelson, D., Obland, M. D., Oetjen, H., Onasch, T. B., Ortega, I., Ottaviani, M., Pekour, M., Prather, K. A., Radney, J. G., Rogers, R. R., Sandberg, S. P., Sedlacek, A., Senff, C. J., Senum, G., Setyan, A., Shilling, J. E., Shrivastava, M., Song, C., Springston, S. R., Subramanian, R., Suski, K., Tomlinson, J., Volkamer, R., Wallace, H. W., Wang, J., Weickmann, A. M., Worsnop, D. R., Yu, X.-Y., Zelenyuk, A., and Zhang, Q.: Overview of the 2010 Carbonaceous Aerosols and Radiative Effects Study (CARES), Atmos. Chem. Phys., 12, 7647-7687, doi:10.5194/acp-12-7647-2012, 2012.
Zhang, R., Khalizov, A. F., Pagels, J., Zhang, D., Xue, H., and McMurry, P. H.: Variability in morphology, hygroscopicity, and optical properties of soot aerosols during atmospheric processing, P. Natl. Acad. Sci., 105, 10291-10296, doi:10.1073/pnas.0804860105, 2008. 